\title{
A Comparison of Several Greatest Common Divisor (GCD) Algorithms
}

\author{
Haroon Altarawneh \\ Albalqa Applied University \\ Salt, Jordan
}

\begin{abstract}
This paper about Greater Common Divisor GCD, the paper shows that there is a lot of algorithms, some of these algorithm is good in timing and make low number of iteration, the other make a lot of iteration with a lot of time! But as we see in the analysis of the algorithms that some of the algorithms is faster than the others in small numbers (like Brute force is faster than Bishop Algorithm in the small numbers, but in the large numbers the Bishop Algorithm is too fast with comparison with the brute force) so the researchers recommend to develop the Bishop algorithm the make it more efficient in computing the GCD for small numbers. In the other hand the Dijkstra algorithm is too close in timing and number of iteration with the Bishop algorithm. But as we see in the analysis the best algorithm to use in computing the GCD in all type of integers is the Extended Euclidean algorithm which makes few loops with small or large numbers.
\end{abstract}

\section{Keywords}

Brute Force Algorithm, Dijkstras Algorithm., Extended Euclidean Algorithm, Lehmers GCD Algorithm, Bishops Method for GCD , Fibonacci GCD's.

\section{INTRODUCTION}

In this paper the researchers will present and analysis the next algorithms of the Greatest Common Divisor (GCD):

1- Brute Force Algorithm.

2- Dijkstras Algorithm.

3- Extended Euclidean Algorithm.

4- Lehmers GCD Algorithm.

5- Bishops Method for GCD.

6- Fibonacci GCD's.

The research will start about history of GCD algorithms, the definition of the GCD, Some Properties of GCD; discuss the selected algorithms for computing GCD, and analysis of these algorithmsIN 300 B.C, the Euclids method for finding GCD for two integers was described. This simple algorithm is often regarded as the grandfather of all algorithms in number theory today. This algorithm will not be discussed in this paper, but we will discuss the mentioned algorithms in the introduction [1].

The Greatest Common Divisor (GCD) of two integers A and $\mathrm{B}$, not both zero, is the largest integer that divides both of them. It is convenient to set $\operatorname{GCD}(0,0)=0$.We assume that $\mathrm{A}$ and $\mathrm{B}$ are nonnegative integers.

For example: $\operatorname{GCD}(3,5)=1$, but $\operatorname{GCD}(3,6)=3$, that means 3 and 5 divide on the common integer 1 which is the greatest integer that divides the two numbers, so with 3 and 6,1 divide 3 and 6 but 3 divide 3 and 6 and 3 is greater than 1 then the $\operatorname{GCD}(3,6)$ is 3 not 1 . you can analysis the number to make sure of the GCD, as example 6 and 12:

$$
\begin{array}{ll}
6 & : 13 \underline{6} \\
12 & : 1234 \underline{6} 12
\end{array}
$$

So the $\operatorname{GCD}(5,12)$ is 6 as shown above. The $\operatorname{GCD}(\mathrm{A}, \mathrm{B}, \mathrm{C}, \ldots$. can be also defined for more than two integers as the largest divisor positive integer shared by all of the number A,B,C... [2]

And here are Some Properties of GCD:

1- Every common divisor of A and B divides $\mathrm{GCD}$ of $\mathrm{A}$ and $\mathrm{B}$.

2- If $m$ is ant integer, the $\mathrm{GCD}(\mathrm{mA}, \mathrm{mB})=\mathrm{m} \mathrm{GCD}(\mathrm{A}, \mathrm{B})$. $\mathrm{EX}: \operatorname{GCD}(2,3)=1, \operatorname{GCD}(2 * 2,3 * 2)=2 *$ $\operatorname{GCD}(2,3)=1 * 2=2$ where $\operatorname{GCD}(4,6)=2$.

3- If $\mathrm{m}$ is a nonzero common divisor of $A$ and $B$ then $\operatorname{GCD}(A / m, B / m)=$ $\operatorname{GCD}(\mathrm{A}, \mathrm{B}) / \mathrm{m}$.

EX: $\operatorname{GCD}(6,12)=6,6$ and 12 divide on 2, $\operatorname{GCD}(6 / 2,12 / 2)=\operatorname{GCD}(3,6)=3$ equal to $\operatorname{GCD}(6,12)=6 / 2=3$.

4- GCD of three numbers $\operatorname{GCD}(\mathrm{A}, \mathrm{B}, \mathrm{C})$ can be computed as $\operatorname{GCD}(\operatorname{GCD}(\mathrm{A}, \mathrm{B}), \mathrm{C})$ $\mathrm{GCD}(\mathrm{A}, \mathrm{GCD}(\mathrm{B}, \mathrm{C}))$. $\mathrm{EX}: \operatorname{GCD}(2,4,6)=2=\operatorname{GCD}(\operatorname{GCD}(2,4), 6)=$ $\operatorname{GCD}(2,6)=2=\operatorname{GCD}(2, \operatorname{GCD}(4,6))=\operatorname{GCD}(2,2)=$ 2.

5- $\mathrm{GCD}(\mathrm{A}, \mathrm{B})=\mathrm{GCD}(\mathrm{B}, \mathrm{A})$. $\mathrm{EX}: \operatorname{GCD}(6,12)=6=\operatorname{GCD}(12,6)$.

6- The GCD of A and B is closely related to their least common multiplier $\operatorname{LCM}(\mathrm{A}, \mathrm{B})$ : where $\operatorname{GCD}(\mathrm{A}, \mathrm{B}) * \operatorname{LCM}(\mathrm{A}, \mathrm{B})=\mathrm{AB}$. $\mathrm{EX:} \operatorname{GCD}(18,12)=6, \operatorname{LCM}(18,12)=36,6 * 36$ $=216=18 * 12$.

7- $\operatorname{GCD}(\mathrm{A}, \mathrm{B})=\mathrm{GCD}(\mathrm{A}, \mathrm{B}+\mathrm{An})$ for all integers $n$.

$\mathrm{EX}: \operatorname{GCD}(2,4)=2, \operatorname{GCD}(2,4+2 * 2)=\operatorname{GCD}(2,8)$ $=2, \operatorname{GCD}(2,4+2 * 3)=\operatorname{GCD}(2,10)=2[3]$. 


\section{Discussion of Selected Algorithms for Computing GCD}

\subsection{Brute Force Algorithm:}

\section{Definition:}

The idea of this algorithm is to try all integers from $\mathrm{n}$ down until finding one that divides $m$ and $n$ evenly[4].

\section{Algorithm:}

1- Take two positive integers $m, n$, where $m<n$.

2- Initialize $\mathrm{i}=\mathrm{m}$.

3- While $(\mathrm{m} \bmod \mathrm{i}<>0$ or $\mathrm{n} \bmod \mathrm{i}<>0)$ do $\mathrm{i}=\mathrm{i}-1$;

$\mathrm{GCD}=\mathrm{i}$

\section{Example:}

$1-\quad \mathrm{m}=6, \mathrm{n}=12$.

2- $\mathrm{I}=6$.

3- $6 \bmod 6=0$ and $12 \bmod 6=0$ then $\mathrm{GCD}=6$.

Code:

var $n, m, i$ : integer;

begin

$\mathrm{m}=4 ; \mathrm{n}=11 ;$

While (m mod $\mathrm{i}<>0$ and $\mathrm{n} \bmod \mathrm{i} \quad<0)$ do

$$
\mathrm{i}=\mathrm{i}-1 \text {; }
$$

$\mathrm{GCD}=\mathrm{i}$

End.

\section{Tracing:}

\begin{tabular}{|c|c|c|}
\hline $\mathrm{m}$ & $\mathrm{N}$ & $\mathrm{i}$ \\
\hline 4 & 11 & 4 \\
\hline & & 3 \\
\hline & & 2 \\
\hline & & 1 \\
\hline
\end{tabular}

$\mathrm{GCD}=1$

\section{Program:}

DIM m, n, i AS INTEGER

INPUT m

INPUT $n$

$\mathrm{i}=\mathrm{m}$

WHILE ((n MOD i $<>0)$ OR (m MOD i $<>0))$

$\mathrm{i}=\mathrm{i}-1$

WEND

PRINT "GCD="; i

\subsection{Dijkstra's Algorithm:}

\section{Definition:}

This algorithm is developed by Dijkstra who is a Dutch mathematician and a computer scientist.

The idea of this algorithm is : if $m>n, \operatorname{GCD}(m, n)$ is the same as $\mathrm{GCD}(\mathrm{m}-\mathrm{n}, \mathrm{n})$. why ? if $\mathrm{m} / \mathrm{d}$ both leave no remainder, then (m$\mathrm{n}) / \mathrm{d}$ leaves no remainder).

The best thing in this algorithm is that it uses the data structure recursion algorithm[5].

\section{Algorithm:}

For $\mathrm{m}, \mathrm{n}>0, \mathrm{GCD}(\mathrm{m}, \mathrm{n})=$

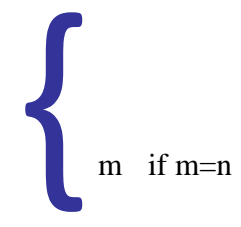

$\mathrm{GCD}(m-n, n) \quad$ if $m>n$

\section{Example:}

1- $\mathrm{m}=4, \mathrm{n}=4: \operatorname{GCD}(4,4)=4$

2- $\mathrm{m}=6, \mathrm{n}=4: \operatorname{GCD}(6,4)=\operatorname{GCD}(6-4,4)=$ $\operatorname{GCD}(2,4)=\operatorname{GCD}(2,4-2)=\operatorname{GCD}(2,2)=2$

3- $\mathrm{m}=4, \mathrm{n}=8: \operatorname{GCD}(4,8)=\operatorname{GCD}(4,8-4)=$ Code: $\operatorname{GCD}(4,4)=4$

var n,m : integer;

$\mathrm{m}=6 ; \mathrm{n}=4$;

Begin 


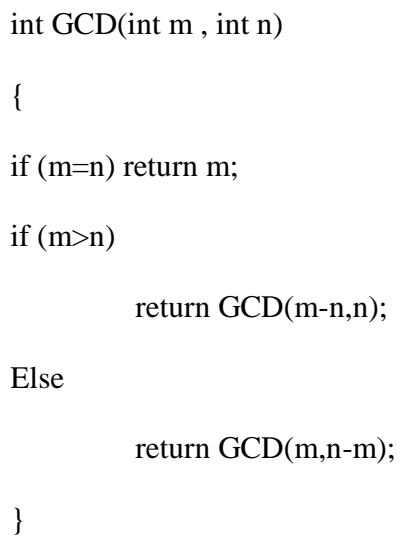

Else return $\mathrm{GCD}(\mathrm{m}, \mathrm{n}-\mathrm{m})$; \}

End.

Tracing:

\begin{tabular}{|c|c|c|}
\hline $\mathrm{m}$ & $\mathrm{n}$ & $\mathrm{GCD}$ \\
\hline 6 & 4 & $\mathrm{GCD}(6,4)$ \\
\hline 2 & 4 & $\operatorname{GCD}(2,4)$ \\
\hline 2 & 2 & $\mathrm{GCD}(2,2)$ \\
\hline & & 2 \\
\hline
\end{tabular}

$\mathrm{GCD}=2$

\section{Program:}

DECLARE FUNCTION GCD (n1 AS INTEGER, n2 AS INTEGER)

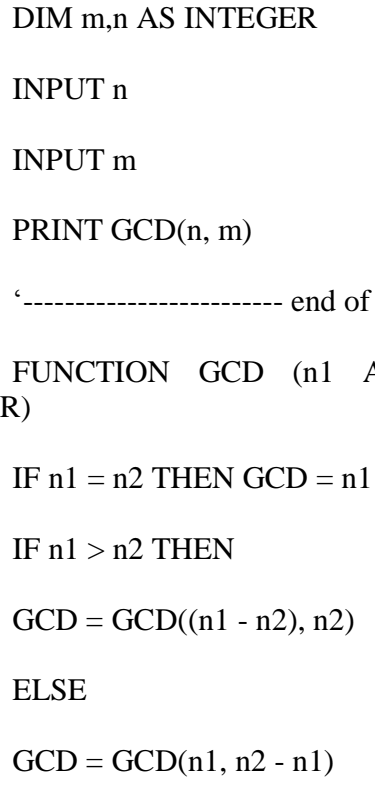

END IF

\section{END FUNCTION}

\subsection{Extended Euclidean Algorithm:}

\section{Definition:}

It is a version of the Euclidean algorithm, input of this algorithm is two positive integers $m, n$, the algorithm computer the GCD as well as integers $\mathrm{A}$ and $\mathrm{B}$ such that $\mathrm{Am}+\mathrm{Bn}=\mathrm{GCD}(\mathrm{m}, \mathrm{n})[6]$.

\section{Algorithm:}

1- input two positive integers $m, n$

2- initialize: $\mathrm{A} 0=1, \mathrm{~A} 1=0, \mathrm{~B} 0=0, \mathrm{~B} 1=1$, $\mathrm{R} 0=\mathrm{m}, \mathrm{R} 1=\mathrm{n}$

3- While R1 $<>0$ do

\{

$\mathrm{q}=[\mathrm{R} 0 / \mathrm{R} 1]$

temp $=\mathrm{A} 0-\mathrm{A} 1 * \mathrm{q}, \mathrm{A} 0=\mathrm{A} 1, \mathrm{~A} 1=$ temp

temp $=\mathrm{B} 0-\mathrm{B} 1 * \mathrm{q}, \mathrm{B} 0=\mathrm{B} 1, \mathrm{~B} 1=$ temp

temp $=\mathrm{R} 0-\mathrm{R} 1 * \mathrm{q} \quad, \quad \mathrm{R} 0=\mathrm{R} 1, \mathrm{R} 1=$ temp

\}

Return $\mathrm{A}=\mathrm{A} 0 \quad, \mathrm{~B}=\mathrm{B} 0 \quad, \mathrm{~g}=\mathrm{R} 0$ (the GCD)

\section{Example:}

$1-\quad \mathrm{m}=5, \mathrm{n}=15$

2- $\mathrm{A} 0=1, \mathrm{~A} 1=0, \mathrm{~B} 0=0, \mathrm{~B} 1=1, \mathrm{R} 0=5, \mathrm{R} 1=15$

3- $\mathrm{R} 1<>0$

$\mathrm{q}=[5 / 15]=0$

$\begin{array}{ll}\text { temp }=1-0 * 0=1 & , \mathrm{~A} 0=0 \\ \text { temp }=0-1 * 0=0 & , \mathrm{~A} 1=1 \\ \text { temp }=5-15 * 0=5 & , \mathrm{R} 0=15\end{array}$

$\mathrm{R} 1<>0$

$\mathrm{Q}=[15 / 5]=3$

temp $=0-1 * 3=-3$

, $\mathrm{A} 0=1 \quad, \mathrm{~A} 1=-3$

temp $=1-0 * 3=1$

, B0 $=0 \quad, \mathrm{~B} 1=1$

temp $=15-5 * 3=0$

, R0=5 , R1=0

$\mathrm{R} 1=0$ exit loop

$\mathrm{A}=\mathrm{A} 0=1$

, $\mathrm{B}=\mathrm{B} 0=0$ 
$\mathrm{Am}+\mathrm{Bn}=\mathrm{GCD}(\mathrm{m}, \mathrm{n})$

$1 * 5+0 * 15=5 \quad$ is true

Code:

var n,m,A0,A1,B0,B1,R0,R1,temp : integer;

$m=5 ; n=15 ;$

Begin

$\mathrm{A} 0=1 ; \mathrm{A} 1=0 ; \mathrm{B} 0=0 ; \mathrm{B} 1=1 ; \mathrm{R} 0=\mathrm{m} ; \mathrm{R} 1=\mathrm{n} ;$

While R1 $<>0$ do

\{

$\mathrm{q}=[\mathrm{R} 0 / \mathrm{R} 1] ;$
temp=A0-A1*q;
$\mathrm{A} 0=\mathrm{A} 1 ;$
$\mathrm{A} 1=\mathrm{temp} ;$
temp=B0-B1*q;
$\mathrm{B} 0=\mathrm{B} 1 ;$
$\mathrm{B} 1=\mathrm{temp} ;$
temp=R0-R1*q;
$\mathrm{R} 0=\mathrm{R} 1 ;$
$\mathrm{R} 1=\mathrm{temp} ;$
Return “A=",A0,"B=",B0,"GCD=",R0;

Tracing:

\begin{tabular}{|c|c|c|c|c|c|c|c|c|}
\hline $\mathrm{M}$ & $\mathrm{n}$ & $\mathrm{A} 0$ & $\mathrm{~A} 1$ & $\mathrm{~B} 0$ & $\mathrm{~B} 1$ & $\mathrm{R} 0$ & $\mathrm{R} 1$ & $\mathrm{q}$ \\
\hline 5 & 15 & 1 & 0 & 0 & 1 & 5 & 15 & 0 \\
\hline- & - & 0 & 1 & 1 & 0 & 15 & 5 & 3 \\
\hline- & - & 1 & -3 & 0 & 1 & 5 & 0 & - \\
\hline
\end{tabular}

\section{Program:}

DIM m, n, a0, a1, b0, b1, r0, r1, temp AS INTEGER
INPUT m

INPUT $n$

$\mathrm{a} 0=1: \mathrm{a} 1=0: \mathrm{b} 0=0: \mathrm{b} 1=1: \mathrm{r} 0=\mathrm{m}: \mathrm{r} 1=\mathrm{n}$

DO WHILE $\mathrm{r} 1<>0$

$$
\begin{aligned}
& \mathrm{q}=\mathrm{INT}(\mathrm{r} 0 / \mathrm{r} 1) \\
& \text { temp }=\mathrm{a} 0-\mathrm{a} 1 * \mathrm{q}: \mathrm{a} 0=\mathrm{a} 1: \mathrm{a} 1=\text { temp } \\
& \text { temp }=\mathrm{b} 0-\mathrm{b} 1 * \mathrm{q}: \mathrm{b} 0=\mathrm{b} 1: \mathrm{b} 1=\text { temp } \\
& \text { temp }=\mathrm{r} 0-\mathrm{r} 1 * \mathrm{q}: \mathrm{r} 0=\mathrm{r} 1: \mathrm{r} 1=\text { temp }
\end{aligned}
$$

LOOP

$a=a 0: b=b 0: g=r 0$

PRINT "GCD=", r0

\subsection{Lehmers GCD Algorithm:}

Definition: An alternate approach to speeding up euclids algorithm is due to lehmer. One notices that when $a$ and $b$ have the same size, the integer part $w$ of the $a / b$ is often single digit.

Assume that $\mathrm{a}, \mathrm{b}$ are very big numbers, ${ }^{\wedge} \mathrm{a},{ }^{\wedge} \mathrm{b}$ are small numbers such that: $a / b=\wedge a / \wedge b$

then the sequence of quotients produced by $\mathrm{EA}(\mathrm{a}, \mathrm{b})$ and by $\mathrm{EA}\left({ }^{\wedge} \mathrm{a}, \wedge^{\wedge}\right)$ will be the same in the beginning, as long as this holds one may compute $\operatorname{EA}(\wedge a, b)$ instead of $\operatorname{EA}(a, b)$ which is much more economical[7].

\section{Algorithm:}

1- INPUT: two positive integers $\mathrm{x}$ and $\mathrm{y}$ in radix $\mathrm{b}$ representation, with $\mathrm{x}>=\mathrm{y}$.

2- OUTPUT: $\operatorname{gcd}(x ; y)$.

1. While $y>=b$ do the following:

1.1 Set $\mathrm{x}^{\wedge}, \mathrm{y}^{\wedge}$ to be the high-order digit of $\mathrm{x}, \mathrm{y}$, respectively ( $\mathrm{y}^{\wedge}$ could be 0$)$.

1.2 $\mathrm{A}=1, \mathrm{~B}=0, \mathrm{C}=0,=\mathrm{D}=1$

1.3 While $\left(\mathrm{y}^{\wedge}+\mathrm{C}\right)<>0$ and $\left(\mathrm{y}^{\wedge}+\mathrm{D}\right) \longleftrightarrow>0$ do the following:

D)

$$
\mathrm{q}=\text { floor }\left(\left(\mathrm{x}^{\wedge}+\mathrm{A}\right)=\left(\mathrm{y}^{\wedge}+\mathrm{C}\right)\right), \mathrm{q}^{\wedge}=\left(\mathrm{x}^{\wedge}+\mathrm{B}\right)=\left(\mathrm{y}^{\wedge}+\right.
$$

If $\mathrm{q} \ll>\mathrm{q}^{\wedge}$ then go to step 1.4.

$$
\mathrm{t}=\mathrm{A}-\mathrm{qC}, \mathrm{A}=\mathrm{C}, \mathrm{C}=\mathrm{t}, \mathrm{t}=\mathrm{B}-\mathrm{qD}, \mathrm{B}=\mathrm{D}, \mathrm{D}=\mathrm{t} \text {. }
$$


$\mathrm{t}=\mathrm{x}^{\wedge}-\mathrm{qy^{ \wedge }}, \mathrm{x}^{\wedge}=\mathrm{y}^{\wedge}, \mathrm{y}^{\wedge}=\mathrm{t}$.

1.4 If $\mathrm{B}=0$, then $\mathrm{t}=\mathrm{x} \bmod \mathrm{y}, \mathrm{x}=\mathrm{y}, \mathrm{y}=\mathrm{t}$;

otherwise, $\mathrm{t}=\mathrm{Ax}+\mathrm{By}, \mathrm{u}=\mathrm{Cx}+\mathrm{Dy}, \mathrm{x}=\mathrm{t}, \mathrm{y}=\mathrm{u}$.

2. Compute $\mathrm{v}=\operatorname{gcd}(\mathrm{x} ; \mathrm{y})$ using Euclids Algorithm:

input $\mathrm{x}, \mathrm{y}$ where $\mathrm{x}>\mathrm{y}$

while $\mathrm{b}<>0$ do the following:

$\mathrm{r}=\mathrm{a} \bmod \mathrm{b}, \mathrm{a}=\mathrm{b}, \mathrm{b}=\mathrm{r}$

3. Return(v).

\section{Example \& Tracing :}

$x=768454923, y=542167814, b=10^{3}$

\begin{tabular}{|c|c|c|c|c|}
\hline $\bar{X}$ & $\mathrm{Y}$ & $q$ & $\mathrm{q}^{\wedge}$ & Precision \\
\hline 768454923 & 542167814 & 1 & 1 & Single (T1) \\
\hline 89593596 & 47099917 & 1 & 1 & Single (T2) \\
\hline 42493679 & 4606238 & 10 & 8 & Multiple \\
\hline 4606238 & 1037537 & 5 & 2 & Multiple \\
\hline 1037537 & 456090 & - & - & Multiple \\
\hline 456090 & 125357 & 3 & 3 & Single (T3) \\
\hline 34681 & 10657 & 3 & 3 & Single (T4) \\
\hline 10657 & 2710 & 5 & 3 & Multiple \\
\hline 2710 & 2527 & 1 & 0 & Multiple \\
\hline 2527 & 183 & & & (Euclids) \\
\hline 183 & 148 & & & (Euclids) \\
\hline 148 & 35 & & & (Euclids) \\
\hline 35 & 8 & & & (Euclids) \\
\hline 8 & 3 & & & (Euclids) \\
\hline 3 & 2 & & & (Euclids) \\
\hline 2 & 1 & & & (Euclids) \\
\hline 1 & 0 & & & (Euclids) \\
\hline
\end{tabular}

(T1)

\begin{tabular}{|c|c|c|c|c|c|c|c|}
\hline $\mathrm{X}$ & $\mathrm{Y}$ & $\mathrm{A}$ & $\mathrm{B}$ & $\mathrm{C}$ & $\mathrm{D}$ & $\mathrm{q} 1$ & $\mathrm{q} 2$ \\
\hline 768 & 542 & 1 & 0 & 0 & 1 & 1 & 1 \\
\hline 542 & 226 & 0 & 1 & 1 & -1 & 2 & 2 \\
\hline 226 & 90 & 1 & -1 & -2 & 3 & 2 & 2 \\
\hline 90 & 46 & -2 & 3 & 5 & -7 & 1 & 2 \\
\hline
\end{tabular}

(T2)

\begin{tabular}{|c|c|c|c|c|c|c|c|}
\hline $\mathrm{X}$ & $\mathrm{Y}$ & $\mathrm{A}$ & $\mathrm{B}$ & $\mathrm{C}$ & $\mathrm{D}$ & $\mathrm{q} 1$ & $\mathrm{q} 2$ \\
\hline 89 & 47 & 1 & 0 & 0 & 1 & 1 & 1 \\
\hline 47 & 42 & 0 & 1 & 1 & -1 & 1 & 1 \\
\hline 42 & 5 & 1 & -1 & -1 & 2 & 10 & 5 \\
\hline
\end{tabular}

(T3)

\begin{tabular}{|c|c|c|c|c|c|c|c|}
\hline $\mathrm{X}$ & $\mathrm{Y}$ & $\mathrm{A}$ & $\mathrm{B}$ & $\mathrm{C}$ & $\mathrm{D}$ & $\mathrm{q} 1$ & $\mathrm{q} 2$ \\
\hline 456 & 125 & 1 & 0 & 0 & 1 & 3 & 3 \\
\hline 125 & 81 & 0 & 1 & 1 & -3 & 1 & 1 \\
\hline 81 & 44 & 1 & -3 & -1 & 4 & 1 & 1 \\
\hline 44 & 37 & -1 & 4 & 2 & -7 & 1 & 1 \\
\hline 37 & 7 & 2 & -7 & -3 & 11 & 9 & 1 \\
\hline
\end{tabular}

(T4)

\begin{tabular}{|c|c|c|c|c|c|c|c|}
\hline $\mathrm{X}$ & $\mathrm{Y}$ & $\mathrm{A}$ & $\mathrm{B}$ & $\mathrm{C}$ & $\mathrm{D}$ & $\mathrm{q} 1$ & $\mathrm{q} 2$ \\
\hline 34 & 10 & 1 & 0 & 0 & 1 & 3 & 3 \\
\hline 10 & 4 & 0 & 1 & 1 & -3 & 2 & 11 \\
\hline
\end{tabular}

Code:

Var b,x,y,xh,yh,q,qh,A,B,C,D : integer;

Begin

$X=768454923, y=542167814, b=10^{3}$;

While $(\mathrm{y}>=\mathrm{b})$ do 


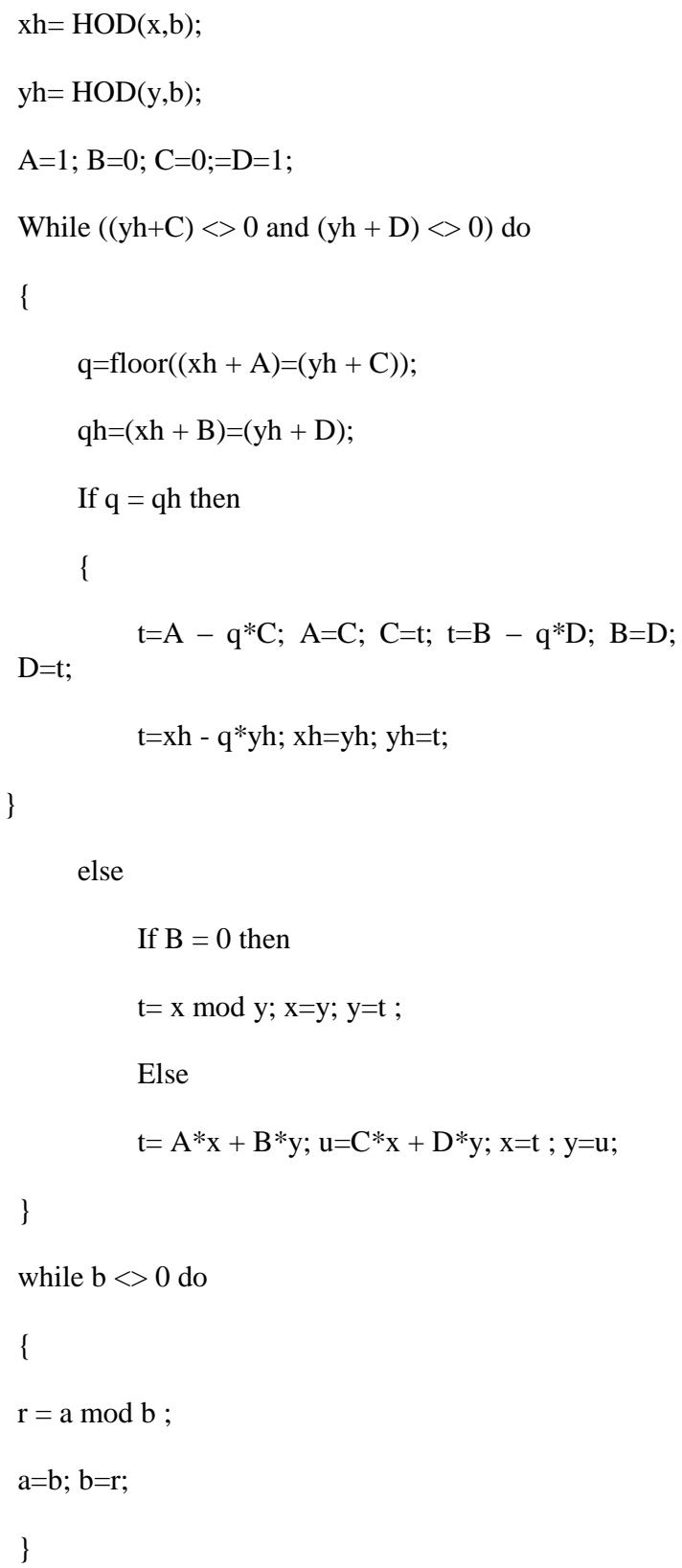

\subsection{Bishop's Method for GCD:}

\section{Definition:}

If a large and small numbers are both multiples of $\mathrm{K}$, them large - small is a multiple of $\mathrm{K}$. note that large-small is smaller than large, so we have reduced the problem to one easier to solve. So we need greatest multiple of large-small and small ... and so on [8].

\section{Algorithm:}

1- input two positive integers $\mathrm{X}, \mathrm{Y}$

2- while $(\mathrm{x} \ll>\mathrm{y})$ do if $(x>y)$ then

$$
\mathrm{x}=\mathrm{x}-\mathrm{y}
$$

else

\{

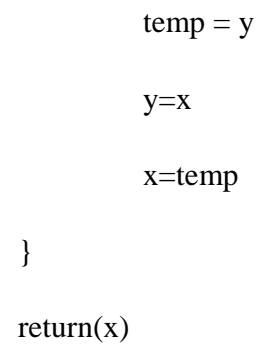

\section{Example:}

1- $\mathrm{X}=30, \mathrm{Y}=45$

2- $\quad X \ll Y$

Is $\mathrm{X}>\mathrm{Y}$ no

Temp $=45$

$\mathrm{Y}=30$

$X=45$

$\mathrm{X} \ll \mathrm{Y}$

Is $\mathrm{X}>\mathrm{Y}$

yes

$X=45-30=15$

$\mathrm{X}<>\mathrm{Y}$

15 < 30

Is $\mathrm{X}>\mathrm{Y}$

no

Temp $=30$

$\mathrm{Y}=15$

$X=30$

$\mathrm{X}<>\mathrm{Y}$

$30<>15$

Is $\mathrm{X}>\mathrm{Y}$

yes

$X=15-30=15$

$\mathrm{X}=\mathrm{Y}$

exit loop $\mathrm{GCD}=\mathrm{X}=\mathrm{Y}=15$

Code:

var $\mathrm{x}, \mathrm{y}$, temp : integer;

Begin

$X=30 ; y=45$; temp $=0$;

While $\mathrm{X}$ < Y do 


$$
\begin{aligned}
& \text { if } \mathrm{X}>\mathrm{Y} \text { then } \\
& \qquad \mathrm{X}=\mathrm{X}-\mathrm{Y} ; \\
& \text { Else } \\
& \qquad \mathrm{Temp}=\mathrm{Y} \text { X; } \\
& \mathrm{X}=\mathrm{Temp} ;
\end{aligned}
$$

End if

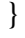

End.

Tracing:

\begin{tabular}{|c|c|}
\hline $\mathrm{X}$ & $\mathrm{Y}$ \\
\hline 30 & 45 \\
\hline 45 & 30 \\
\hline 15 & 30 \\
\hline 30 & 15 \\
\hline 15 & 15 \\
\hline
\end{tabular}

Program:

DIM X, Y, TEMP AS INTEGER

INPUT X

INPUT Y

DO WHILE $X \ll Y$

IF $X>Y$ THEN

$X=X-Y$

ELSE

$\mathrm{TEMP}=\mathrm{Y}$

$\mathrm{Y}=\mathrm{X}$

$\mathrm{X}=\mathrm{TEMP}$

END IF
LOOP

PRINT "GCD="; X

\subsection{Fibonacci GCD's: Definition:}

Fibonacci numbers are then numbers in the series: $n 1, n 2$, $\mathrm{n} 3=\mathrm{n} 1+\mathrm{n} 2, \mathrm{n} 4=\mathrm{n} 2+\mathrm{n} 3, \mathrm{n} 5=\mathrm{n} 3+\mathrm{n} 4, \ldots$ so that the numbers are 0,1 , $1,2,3,5,8,13,21,34,55, \ldots$ the Fibonacci GCDs are the GCD of two Fibonacci numbers and the result is also a Fibonacci number[8].

\section{Algorithm and Example:}

You can use ant of the GCDs algorithm to calculate the GCD, this algorithm is only to denote that the result is a Fibonacci number. As example we use the euclids GCD algorithm:

$\mathrm{F} 1=34, \mathrm{f} 2=8$

$\operatorname{GCD}(34,8)$

$34 \bmod 8=2$

$8 \bmod 2=0$

So $\operatorname{GCD}(34,8)=2$ which is a Fibonacci number.

\section{Analysis of algorithms:}

3.1 Time Consume:

The next table and graph show the timing in MS for the algorithms for several integer numbers length:

\begin{tabular}{|c|c|c|c|c|}
\hline Algorithm & 2 Digits & 4 digits & 6 digits & 8 digis \\
\hline $\begin{array}{c}\text { Brute Force } \\
\text { Algorithm }\end{array}$ & $0 \mathrm{~ms}$ & $9 \mathrm{~ms}$ & $178 \mathrm{~ms}$ & $\begin{array}{c}\text { Too } \\
\text { long }\end{array}$ \\
\hline $\begin{array}{c}\text { Dijkstra's } \\
\text { Algorithm }\end{array}$ & $5 \mathrm{~ms}$ & $2 \mathrm{~ms}$ & $0 \mathrm{~ms}$ & $1 \mathrm{~ms}$ \\
\hline $\begin{array}{c}\text { Extended Euclidean } \\
\text { Algorithm }\end{array}$ & $1 \mathrm{~ms}$ & $1 \mathrm{~ms}$ & $0 \mathrm{~ms}$ & $2 \mathrm{~ms}$ \\
\hline $\begin{array}{c}\text { Bishop's Method for } \\
\text { GCD }\end{array}$ & $3 \mathrm{~ms}$ & $8 \mathrm{~ms}$ & $1 \mathrm{~ms}$ & $5 \mathrm{~ms}$ \\
\hline
\end{tabular}




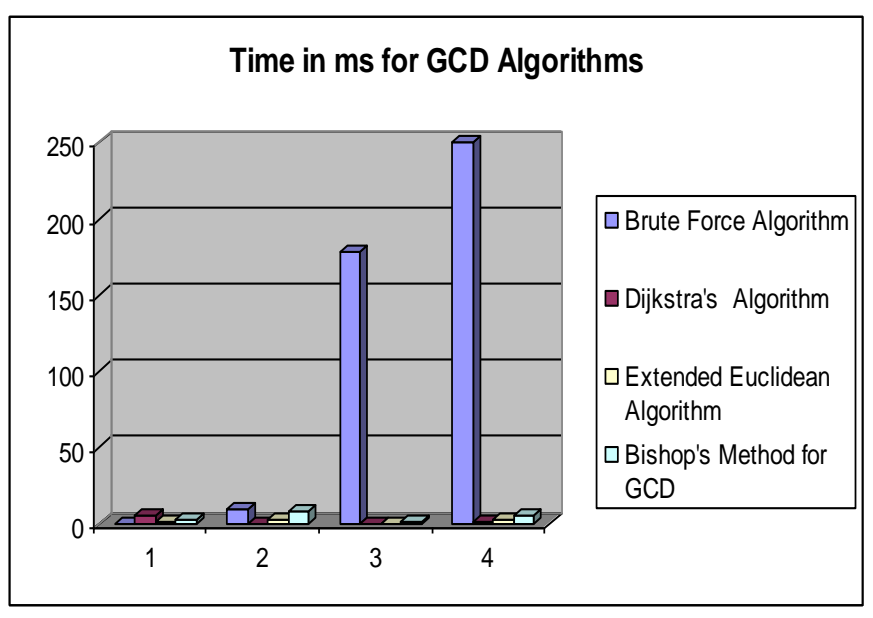

As seen in the above graph that the brute force algorithm in number that are 6 and more digits it toke a lot of time to get the result, in the other hand the Extended Euclidean algorithm takes less time when the numbers are more than 6 digits.

\subsection{Number of loops:}

The next table and graph show the number of loops for the algorithms for several integer numbers length:

\begin{tabular}{|c|c|c|c|c|}
\hline Algorithm & $\begin{array}{c}2 \\
\text { Digits }\end{array}$ & 4 digits & 6 digits & 8 digis \\
\hline $\begin{array}{c}\text { Brute Force } \\
\text { Algorithm }\end{array}$ & 11 & 1232 & 125472 & 1236548 \\
\hline $\begin{array}{c}\text { Dijkstra's } \\
\text { Algorithm }\end{array}$ & 9 & 44 & 55 & 54 \\
\hline $\begin{array}{c}\text { Extended } \\
\text { Euclidean } \\
\text { Algorithm }\end{array}$ & 6 & 7 & 12 & 18 \\
\hline $\begin{array}{c}\text { Bishop's Method } \\
\text { for GCD }\end{array}$ & 14 & 50 & 66 & 71 \\
\hline
\end{tabular}

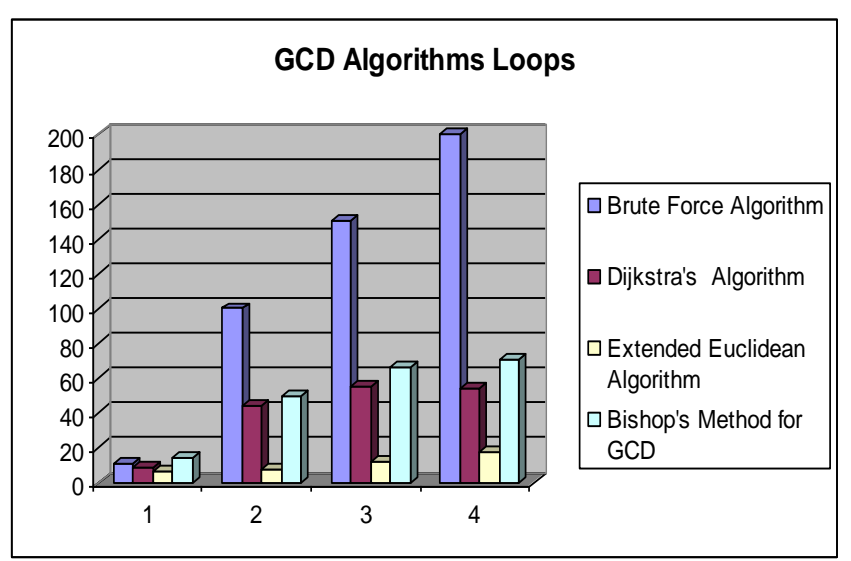

The graph above shows the number of loops that the algorithms take to find the answer. The Brute force algorithm make a lot of loops to get the answer in the numbers that more than 2 digits, in the other hand the Extended Euclidean algorithm make few loops to get the answer.

\section{CONCLUSIONS:}

As seen in this paper about Greater Common Divisor GCD that there is a lot of algorithms, some of these algorithm is good in timing and make low number of iteration, the other make a lot of iteration with a lot of time! But as we see in the analysis of the algorithms that some of the algorithms is faster than the others in small numbers (like Brute force is faster than Bishop Algorithm in the small numbers, but in the large numbers the Bishop Algorithm is too fast with comparison with the brute force) so the researchers recommend to develop the Bishop algorithm the make it more efficient in computing the GCD for small numbers.

\section{REFERENCES}

[1] Handbook of Applied Cryptography, by A. Menezes, P. van Oorschot, and S. Vanstone, CRC Press, 1996.

[2] eLiteral The Moving Constant available at: http://services.eliteral.com/digital-certificatemumbai/chap14.php

[3] Washington University, St. Louis available a: http://www.cs.wustl.edu/ kjg/cs101/Notes/Recursion/recur sion.html

[4] Centre for Information Security and Cryptography available at: http://cisac.math.ucalgary.ca/news_events/hugh/talks/soren son.pdf

[5] National Institute of Standards and Technology available at: http://www.nist.gov/dads/

[6] Computer Science Ben Gurion University of the Negev available at: http://www.cs.bgu.ac.il/ berend/teaching/Intro2CS/examples/main.h tml 